\title{
4
}

\section{A Stakeholder Model for Managing Knowledge Assets in Organizations}

\author{
Constantine Imafidon Tongo \\ Department of Human Resource Management and Organizational Behaviour, Lagos \\ Business School, Pan African University, Ajah, Victoria Island, Lagos \\ Nigeria
}

\section{Introduction}

The valuable and visible things that were made centuries ago to make life meaningful for men in the earth never fell from the skies; they were first of all produced in human minds, and those that will be created in future shall also spring from the same source. The above adage suggests that the specific knowledge required to produce these things in olden days preceded their physical existence. Nevertheless, from time immemorial, knowledge has played the second fiddle to other factors of production like land, capital and labour within organizations. This is a bit absurd, especially when we consider the fact that there is no single product or service that organizations can offer to markets without being first of all produced in the minds of people in the form of a specified knowledge needed for it to see the light of day.

Therefore one wonders that it is only a few years ago that knowledge as an asset was brought into the mainstream of organizational theory. It is now very clear that the primary business of organizations is to sell knowledge based products and that competitiveness hinges on the effective management of all organizational knowledge assets (Grover and Davenport, 2001; Hillman and Keim, 2001; Alavi and Leidner, 2001; Anand, et. al., 2002; Quinn, 2005).

Given the above truism, how can knowledge assets be effectively managed in organizations? This question is very pertinent since the knowledge management literature is rife with the idea that these assets can exist in various forms (Falconer, 2011; Lytras and Ordonez de Pablos, 2009; Schiuma, 2009; Alavi and Leider; 2001; Becerra-Fernandez and Sabherwal, 2001; Akbar, 2003). Hence they all need to synergistically interact and depend on each other for the promotion of organizational effectiveness. However, in order to achieve synergy in the management of knowledge assets, it is important to know the specific roles that each knowledge asset will be playing within organizations. This can only be achieved by extensively differentiating them according to the purpose that they are meant to serve in organizations.

Previously, the process of differentiating knowledge assets has been mainly based on the forms by which they exist (i.e. tacit and explicit knowledge), their sources (i.e. knowledge generated within organizations and externally generated knowledge) and where they are stored (e.g. knowledge in human mind, organizational structure, culture and process, etc.). However, differentiation of knowledge assets in terms of what forms they exist, their 
sources and where they are stored in organizations would not appreciably promote their effective management; as these do not inform us about the usefulness of these assets. Rather, knowing the purpose for accumulating each of them should be the pre-requisite for managing them successfully in organizations. Like any other organizational asset or resource, the purpose of all knowledge assets must be well articulated by managers before they can be properly coordinated to promote organizational effectiveness.

Nevertheless, contemporary knowledge management theorists have not yet unanimously defined the purpose of the different forms of organizational knowledge assets. According to Grover and Davenport (2001), knowledge managers often take a highly inconclusive approach to the management of knowledge assets. In practice, what they actually manage under the banner of knowledge management is a mix of knowledge information, and unrefined data- in short, whatever any knowledge manager finds useful and easy to store in an electronic repository (Grover and Davenport, 2001). Indeed, this uncoordinated approach to the management of knowledge assets would not yield any meaningful results. Nonetheless, it suggests that modern knowledge managers do not really know the purpose of all the different organizational knowledge assets at their disposal.

Presently, there are three main types of organizational knowledge assets (i.e. structural knowledge, human knowledge and relational knowledge) that the current knowledge management literature recognizes; and only the purpose of one of them has been well defined by the literature (De Long and Fahey, 2000). That asset is termed relational knowledge or relational capital. Its purpose is to build better relations with primary stakeholders like employees, customers, suppliers, shareholders and communities (Hillman and keim, 2001). The purpose of the other knowledge assets (i.e. structural knowledge and human knowledge) has not yet been articulated in relation to the goals of any modern organization.

Since most modern organizations thrive to satisfice the interests of their stakeholders in order to survive (March and Simon, 1958; Cyert and March, 1963; Simon, 1982; Freeman, 1984; Hillman and Keim, 2001; Schneider, 2002) and only relational knowledge or capital has been known to pursue this objective; it therefore means that if other knowledge assets are tailored towards other disparate objectives, they would lack the capacity of being synchronized with relational knowledge or capital for the benefit of stakeholders.

In other words, the objective of relational knowledge and those of other knowledge assets (i.e. structural knowledge and human knowledge) could be diametrically opposed to each other. Thus, while relational knowledge seeks to satisfice stakeholders' interests; the objectives of other knowledge assets may counteract the mission of relational knowledge. Consequently, the long term wealth generating capacity of the different organizational knowledge assets would not be effectively synchronized to meet stakeholders' interests. This will be very counter productive for any organization.

Therefore I assert in this article that despite the variability of these assets, their ultimate purpose is to satisfice stakeholders' interests. As a matter of fact, the accumulation of any knowledge asset by organizations is worthless unless it is meant to meet the needs of some stakeholders.

Based on this view of organizational knowledge assets, the objective of this article is to differentiate them according to their ultimate purpose, which is satisficing stakeholders' interests; as well as provide mechanisms for their integration so that they could be effectively managed.

This is particularly important because recent studies have been placing more emphasis on the analysis of the interactions and interdependencies of the various types of organizational 
knowledge assets (Bontis, 1996; Ordonez de Pablos, 2001; Tsan and Chang, 2005; Falconer, 2011). However, much more detailed research involving the purpose of the different types of knowledge assets is needed to understand their nexus with each other as they create value for organizations.

Further more, while many past studies have attempted to provide key indicators that can track down the performance of knowledge assets; aspersions are now been cast on these studies because they have woefully failed to accurately discern the purpose of all the knowledge assets. Without defining the purpose of each of them, it will be impossible to derive the key indicators that can assess their performance. Since this article is geared towards differentiating them according to their purpose, we can be more certain that this purpose driven differentiation would significantly help to derive the key indicators required for their performance. This shall be treated in the latter part of this article.

In order to achieve the objective of this article, it shall be divided into six sections. The first section will present the previous taxonomy for knowledge assets. Since knowledge assets are strategic resources (Lytras and Ordonez de Pablos, 2009; Tongo, 2010; Schiuma, 2009); the second section shall attempt to link the management of knowledge assets to business strategy. This shall be followed by a discussion on the rationale for proposing the stakeholder model for managing organizational knowledge assets in the third section. A detailed analysis of the model shall ensue in section four. The fifth section would cover the theoretical and practical managerial implications of the model and then the sixth section concludes the article.

\section{Previous taxonomy for organizational knowledge assets}

Organizational knowledge assets, otherwise known as intellectual capital in the knowledge management literature have been construed as any information, belief or skill that the organization can apply to its various activities (Anand, et. al., 2002). According to this view, it can exist in multiple forms. It may refer to the specific scientific knowledge possessed by an organization's research department, or information about an oversee market, or skills that enable managers to make effective decisions in rapidly changing environments (Anand, et. al., 2002). However, irrespective of the various forms in which organizational knowledge exists, it has been broadly differentiated into two types. These are tacit knowledge and explicit knowledge (Polanyi, 1962, Nonaka, 1994; De Long and Fahey, 2000; Markus, 2001; Anand et. al., 2002).

The tacit dimension of knowledge comprises both cognitive and technical elements (Nonaka, 1994). The cognitive element refers to an individual's mental models consisting of mental maps, beliefs, paradigms, and viewpoints. The technical component consists of concrete know how, crafts and skills that apply to a specific organizational context (Alavi and Leidner, 2001). According to De Long and Fahey (2000), tacit knowledge is what we know but cannot explain. Consider, for example, a quality control engineer who through years of experience can identify the quality of a newly manufactured engine by its sound and vibrations on testing the engine. Such tacit knowledge cannot be transferred through a written document, and yet it is very important in the organization (Anand, et. al., 2002).

Explicit knowledge, on the other hand, is articulated, codified, and communicated in symbolic form and/or natural language (Alavi and Leidner, 2001). Explicit knowledge can easily be communicated and shared among individuals. For instance, information about 
market size and regulations in an overseas market can be precisely transferred to a report that can be shared within the organization (Anand, et. al., 2002).

It is important to note that both tacit and explicit knowledge are stored within individuals, organizational systems and processes. Tacit knowledge that exists within individuals is referred to as human knowledge or human capital. Human knowledge is the combined knowledge, skill, innovativeness and ability of individuals to realize organizational tasks and goals (Tongo, 2010; Skandia, 1996; Alas, 2009; Joia and Sanz, 2009; De Long and Fahey, 2000). It also includes wisdom, experience, intuition, and even spirituality of organizational members (Lytras and Ordonez de Pablos, 2009). Human knowledge is the property of individual employees which does not belong to the corporate entity (Tongo, 2010; Lytras and Ordonez de Pablos, 2009). Even though employees may possess some explicit knowledge alongside their unique tacit knowledge, such explicit knowledge is not part of human knowledge because it is common to some or the entire members of the organization.

Knowledge that is explicit and common to organizational members is called structural knowledge or capital. Structural knowledge signifies knowledge assets that remain in the organization when it does not take into consideration human knowledge (Ordonez de Pablos, 2009). Structural knowledge connotes organizational knowledge that has moved from individuals or from the relationships between individuals embedded in organizational systems and processes, such as organizational routines, policies, culture, or structure (Lytras and Ordonez de Pablos, 2009).

According to Lytras and Ordenez de Pablos, structural knowledge can be further broken down into technological knowledge and organizational knowledge. Technological knowledge represents industrial and technical knowledge, such as results from research and development and process engineering. Organizational knowledge includes all aspects that are related to the organization of the company and its decision making capabilities and processes. For instance, organizational knowledge comprises organizational culture, organizational structure design, coordination mechanisms, organizational routines, planning and control systems, among others (Bontis, Chong, and Richardson, 2000; Skandia, 1996).

Apart from human and structural knowledge, the literature on knowledge management also recognizes another class of knowledge assets. It is termed relational knowledge or capital. It is also called social capital or social knowledge by some knowledge management theorists (Anand, et. al; 2002; De Long and Fahey; 2000). Unlike human and structural knowledge, relational knowledge can exist in both explicit and tacit forms (Anand, et. al; 2002). Explicit relational knowledge can be obtained from external sources through the use of impersonal communication media such as electronic data interchanges, as well as faxes and letters. On the other hand, tacit relational knowledge requires personal communication that allows for direct and intense interaction among individuals (Anand, et. al., 2002).

Both the explicit and tacit forms of relational knowledge constitute the value of organizational relationships. In general it has been accepted that these relationships are mainly focused on parties that are external to the organization. This includes customers, suppliers, shareholders, etc. (Ordonez de Pablos, 2005). Nevertheless, it must be appreciated that the relationship of an organization with its employees creates value. So for this strategic reason it is necessary to put them in mind. Therefore, to advance in the study of relational knowledge, it is convenient to differentiate between internal relational knowledge and external relational knowledge (Ho, 2007; and Ordonez de Pablos, 2009). 
Internal relational knowledge includes the value of the strategic relationships created between the organization and its employees (Menon and Pfeffer, 2003; Lytras and Ordonez, de Pablos, 2009). External relational knowledge represents the external perspective of relational knowledge and includes social relations of the organization with principal agents: customers, suppliers, shareholders, local government and communities, etc. (Lytras and Ordonez, de Pablos, 2009; Ho, 2007; Menon and Pfeffer, 2003).

Based on the stakeholder theory (Freeman, 1984); a firm can only exist through the interaction, transactions and exchanges carried on with those who have vested stakes in it. In the long run the firm must operate in such a way that each stakeholder is satisfied. The primary goal of the firm is survival, the more dissatisfied its stakeholders are, the more certain it is that the company's activities will cease (Freeman, 1984; Carroll, 1989; Nasi, 1982; 1995). Therefore, the long term wealth generating capacity of organizational knowledge assets can only be guaranteed when potential and existing stakeholders are satisfied (Stewart, 1997; Nielsen, et. al., 2009; Joia and Sanz, 2009; Schiuma, 2009; Lytras and Ordonez de Pablos, 2009; Hillman and Kiem, 2001).

Given the importance of satisficing the needs of stakeholders, only relational knowledge cannot achieve this goal; however, the contemporary knowledge management literature has inadvertently restricted both human knowledge and structural knowledge from undertaking the task of meeting stakeholders' interests. A growing number of researchers and consultants have argued that relational knowledge is the only valid notion of knowledge that managers should be concerned with (De long and Fahey, 2000). Hence the literature has failed to incorporate the purpose of human and structural knowledge into the overall organizational goal of putting stakeholders' interests at the centre of business activities. This shortfall shall be arrested by the latter sections of this article. But before this issue is treated I shall first of all link knowledge management to business strategy. This is important because organizational knowledge assets are strategic resources (Lytras and Ordonez de Pablos, 2009; Tongo, 2010; Schiuma, 2009) and the consideration of all stakeholders of organizations borders on the pursuance of a particular business strategy.

\section{Linking knowledge management to business strategy: Past, present and future}

Every approach to strategy conceives sources of wealth creation and the essence of the strategic problem faced by organizations differently (Teece, et.al., 1997). The competitive forces' approach pioneered by Porter (1980), views the strategic problem in terms of industry structure, entry deterrence, and positioning; game theoretic models see the strategic problem as one of interaction between rivals with certain behavioural expectations about each other; resource based perspective asserts that long run superior performance is associated with the possession of scarce, valuable and inimitable firm-specific resourceshuman, material and physical resources (Barney, 1991; Teece, et. al., 1997; Penrose, 1959; Wernerfelt, 1984; Studdard and Darby, 2011). However, the knowledge based perspective to strategy, which is the crux of this study, postulates that the services rendered by these firm specific resources is basically a function of the knowledge assets possessed by the firm (Alavi and Leidner, 2001; Grant, 1996).

This position stems from the notion that knowledge as a focal asset creates unique advantages for governing economic activities through a logic that is very different from traditional resources' management. Unlike other resources that are governed by the law of 
diminishing returns; every additional unit of knowledge that is effectively utilized results in a marginal increase in performance (Malhotra, 2000). Consequently, the success of modern corporations is often attributed to the fact that every additional unit of knowledge based product or service would result in an increase in marginal returns (Malhotra, 2000).

This therefore implies that knowledge must be seen as the most important factor of production. However, just as not all forms of labour and material are required by every organization, the type of knowledge required by each business entity must be tailored towards its own unique peculiarities. Consequently, in order to effectively harness knowledge as a factor of production, each business organization must be able to accumulate certain "knowledge assets" that are relevant and specific to its diverse operations (Tongo, 2008; Tongo, 2010).

From a practitioner's perspective, much of the work undertaken on knowledge management has been accomplished without immense change on how organizations do business (Grover and Davenport, 2001). Nevertheless, organizations that have reached the initial plateau of knowledge management now realize that the long run complete success at using knowledge for business advantage requires change in many core aspects of business (Grover and Davenport, 2001). In the first phase, the emphasis was on the knowledge management project. According to Grover and Davenport, projects are a good way to get started with knowledge management, but they are by definition peripheral to the rest of the business. Projects "bottle up" knowledge and treat it as something separate. What firms must do in the second phase of knowledge management is to integrate it with business strategy (Grover and Davenport, 2001).

In this regard, the definition and formulation of a business strategy aimed to support and drive organization's value creation in global business have to consider the nature of knowledge assets and its relationship with business strategy (Schiuma, 2009). This means that the identification of the strategic knowledge assets at the basis of organizational effectiveness needs to be taken into account; both as intrinsic objects of business strategy and as instrumental lever to achieve strategic outcomes (Schiuma, 2009). With respect to the Schiuma's assertion, organizations can adopt two main approaches in designing strategy: (i) managers can explicitly and directly focus their attention on knowledge assets and include their development in the objectives of the business strategy or (ii) managers can focus the strategy definition around business and performance objectives and afterwards identify the strategic organizational knowledge resources grounding the achievement of targeted strategic objectives (Schiuma, 2009).

It suffices to state that while in the first approach, the knowledge assets available to the organization are the main drivers of its strategic direction; the second approach peripherally integrates knowledge assets into the mainstream of business strategy. In other words, implied in this latter approach is the second fiddle which knowledge assets play in relation to other organizational resources; as they are only tangentially considered after other resources must have been tailored towards the achievement of strategic goals. Conversely, the first approach implies that organizational strategic design stems from its knowledge assets. However, very little attempts have been made to link up business strategy to knowledge assets management (Grover and Davenport, 2001). Hence the first approach to strategy design as outlined above by Schiuma has been largely ignored.

Presently, the knowledge management literature has only paid an over arching emphasis on the second approach of strategy design which has precisely relegated knowledge assets to the background. The balance scorecard which is the most renowned contemporary business 
model that attempts to link knowledge management to business strategy is a product of this second approach.

The balance scorecard is a strategic planning and management model that aligns business activities to the vision and strategy of the organization. It was developed by Kaplan and Norton (1996), as a performance measurement framework that added strategic nonfinancial performance measures to traditional financial metrics to give managers and executives a more "balanced" view of organizational performance.

According to Kaplan and Norton (1996), the balance score card retains traditional financial measures, but financial measures only tell the story for industrial age organizations for which investments in long term capabilities and customer relationships were not critical for success. These financial measures are inadequate, however, for driving knowledge based organizations towards the creation of future value through investment in customers, suppliers, employees, processes, technology and innovation (Kaplan and Norton, 1996).

The balance scorecard suggests that business strategy must be viewed from four perspectives, and that organizations should develop metrics, collect data and analyze them relative to each of these perspectives.

The four perspectives are (i) learning and growth perspective- which focuses on employee training (ii) business process perspective- focusing on internal business processes (iii) customer perspective- dealing with the need to satisfy customers (iv) financial perspectivepertains to timely and accurate provision of financial data to investors (Kaplan and Norton, 1996).

While the balance score card acknowledges the importance of building the capacities of some intangible or knowledge assets, especially those derived from the three non- financial perspectives in order to promote the future growth of organizations; it fails to see the accumulation of these knowledge assets as the basis for strategy design.

From its point of view, strategy design is about integrating the four perspectives in a way that leads to the satisfaction of three business stakeholders. These are investors, customers and employees (Kaplan and Norton, 1992, 1993, 1996). Apart from the fact that other important stakeholders like government and host community are not covered by the analysis of the balance score card; it accords little or no significance to the role that organizational knowledge assets could play in promoting stakeholders' welfare.

Hence the balance score card actually hinges on the resource based view, rather than the knowledge based view of the firm. It proposes that through the efficient management of financial and non- financial resources of the firm; investors, customers and employees could be satisfied through a business strategy that seeks their diverse interests. However, this business strategy is not fundamentally derived from the knowledge assets available to the organization; it is more or less designed around financial and non-financial resources of the firm. It is for this reason that the balance score card centers around Schiuma's (2009) second approach to strategy design as described above.

More recent business models have been proposed for the strategic management of knowledge assets. The Skandia Navigator (Edvinsson and Malone, 1997); Intangible Assets Monitor (Sveiby, 1997); Danish guideline for Intellectual Capital Accounting developed by the Danish Ministry of Science, Technology and Innovation and the Intellectual Capital Report (Ordonez de Pablos, 2004) are examples of these models. Unlike the balance score card, these other models were mainly designed for measuring the performance of organizational knowledge assets, but they had little or nothing to do with the mapping out of the strategic direction of organizations. Organizational strategy design was never the 
preoccupation of these more recent business models. They only provided many disparate indicators that could be used in tracking down the performance of knowledge assets in organizations. Besides the very tenuous relationship that these business models have with business strategy; they were not unanimous in defining the purpose or role of each of the different knowledge assets in relation to all stakeholders' interests. Given this scenario, what then do these business models portend for the effective management of knowledge assets? First of all, these business models are grossly inadequate in providing the key indicators required for measuring the performance of knowledge assets since they have largely ignored the interests of some organizational stakeholders.

Secondly, ignoring the interests of some stakeholders may threaten the long term survival of organizations and this is precisely what managers of organizational knowledge assets should seek to avoid (Hillman and Kiem, 2001).

Thirdly, without integrating the long term wealth generating capacity of knowledge assets into business strategy it will be impossible to ascertain how they create value for organizations (Andriessen, 2004). In support of this notion, strategy researchers have found out that organizational value creation derives in large part from intangible assets such as organizational learning, grand equity, and reputation (Penrose, 1959; Rumelt, 1984, 1987; Barney, 1986; Spender, 1994; Grant, 1996); and knowledge is arguably the most important intangible asset that firms possess (Penrose, 1959; Winter, 1988).

Therefore because the three points highlighted above would not promote the effective management of knowledge assets towards long term organizational competitiveness; I therefore developed a model that recursively links the different knowledge assets to a business strategy that seeks to satisfice stakeholders' interests. This model is referred to as the "stakeholder model of organizational knowledge assets" in this article. The subsequent section provides the basis for the necessity of the model.

\section{Stakeholder model of organizational knowledge assets}

The recent emphasis on knowledge assets as the main driver of organizational value creation has its own historical antecedents. It is imperative that these antecedents be briefly reviewed in order for us to understand why knowledge assets should drive the process of creating organizational value.

Prior to the post industrial period i.e. before the end of World War II, managers thought they operated within a "closed system" that was made up of two main parties- management and employees. Competitors ought to be a third party, but the business environment that preceded the post industrial period was not quite competitive, and so businesses were somewhat insensitive to the activities of competitors. Therefore the only two parties existing within the so called "closed system" of businesses were assumed to be primarily motivated by the need to satisfy their own selfish interests.

The above point was made very clear by Adam's Smith rational economic man concept and his theory of the firm. According to him, while the managers on one hand would seek the maximization of profits for their owners; employees on the other hand sought maximization of their economic gains. However, the selfish tendencies of both parties were only implicitly implied by Elton Mayo's perspective of the human nature and organizational functioning. But it suffices to state that Mayo's social man could only attain psychological uplifting if his social needs at work are satisfied as long as this does not undermine the maximization of profits that the organization pursues. In other words, while the social man is basically 
concerned with his own selfish social needs, the firm that employs him can only accommodate the satisfaction of these social needs provided its own profits are not tampered with.

Hence the "closed system" that both classical management and human relations theorists espoused before the post industrial period was chiefly concerned with satisfying the selfish interests of just the two parties- management and employees. However, the changing business environment that ushered in the post industrial economy and the subsequent need to view organizations as "open systems" made it expedient for organizations to consider other stakeholders (competitors, suppliers, consumers, government, society e.t.c) of their businesses, apart from management and employees that were hitherto relegated to the background. These stakeholders became increasingly important for business survival. It therefore became imperative for businesses to be socially responsible to these stakeholders. Consequently, the theoretical landscape of management was altered during the post industrial period by those who thought that businesses could only survive through paying substantial attention to their entire stakeholders. This implies that organizations must be viewed as "open systems" which can affect and be affected by many stakeholders outside its boundaries. Renowned management scholars like Robert Katz, Daniel Kahn, William Scott, James Thompson, Fremont Kast, James Rosenzweig Michael Hannan, John Freeman e.t.c belonged to this management school of thought (Shafritz and Ott, 1996). Due to constraints posed by paper space it will be impossible to discuss some of the unique contributions of these management scholars to the above discussion.

Nevertheless, one debate that typifies the post industrial period and still lingers in mainstream economics and management pertains to the overall motive of businesses that now have to function as "open systems". Are they required to maximize profits given the fact that they need to satisfy a number of stakeholders with diverse interests?

Friedman (2002) posits that profit maximization is the principal responsibility of businesses. According to him, those who proclaim that business must have a "social conscience" are preaching pure and adulterated socialism. For Friedman (2002), profit maximization should take care of all the social needs of business' stake holders.

Freeman (2002), disagrees with the above position. Rather he asserts that managerial capitalism is better served by extending the fiduciary relationship from shareholders to include other stakeholders. Business organizations have stakeholders, that is, groups and individuals who benefit from or are harmed by business activities and whose rights are violated or respected by corporate actions (Freeman, 2002).

Albeit, in spite of the heated debates for or against the profit maximization motive of businesses which this article is less concerned about, it is important to note that for the very first time in management history the moral basis or ethical dimension of managing businesses was brought to the fore. And this occurred during the post industrial period.

During the post industrial period, organizations were seen as "open systems" that made use of only tangible resources- land, machines, labour, material, money, e.t.c.- to satisfy the diverse interests of their stakeholders. However, the dawning of the $21^{\text {st }}$ century ushered the global business community into an era of the knowledge economy in which knowledge -an intangible resource- has replaced the traditional factors of production to become the most strategic resources needed for satisfying the pluralized interests of business stakeholders (Chang and Lee, 2007; Houghton and Sheetan, 2000; Hsu, 2009).

Nations are currently being forced to compete in a global knowledge economy where ideas, information and knowledge have no boundaries, but are instead multiplying at a fast pace 
(Petty and Guthrie, 2000). In this knowledge economy, information and knowledge are seen as the principal drivers of value creation and competitive advantage, generating the increasingly critical intangible assets of contemporary organizations. Therefore making the management of knowledge assets very imperative (Cuganesan, 2005).

It is now commonly believed that building better relations with primary stakeholders like employees, customers, suppliers, and communities (Freeman, 1984), could lead to increased shareholders' wealth through the accumulation of knowledge assets that can be sources of competitive advantage (Hillman and Kiem, 2001; Saenz and Gomez, 2008). These knowledge assets in turn lead to a positive relationship between stakeholder management and shareholder value, wherein effective stakeholder management leads to improved financial performance (Hillman and Kiem, 2001; Saenz and Gomez, 2008).

Going by these findings, how can synchronization of the different knowledge assets (i.e. structural knowledge, human knowledge and relational knowledge) towards the satisficing of stakeholders' interests for organizational value creation be achieved? In this article, it is believed that this could be achieved by the development of a business strategy that links the long term wealth generating capacity of highly differentiated and integrated forms of these knowledge assets to the ultimate goal of meeting the diverse interests of stakeholders. This is depicted in the next section. This section shall differentiate and integrate the various facets of the stakeholder model. There after some light will be shed on the theoretical and practical managerial implications of the model.

\section{Differentiating and integrating knowledge assets by stakeholder model}

The rationale for the differentiation of organizational knowledge assets stems from Simon's (1991) principle of bounded rationality. This principle recognizes that the human brain has limited capacity to acquire, store and process knowledge. The result is that efficiency in knowledge production requires that individuals specialize in particular areas of knowledge (Grant, 1996). This therefore implies that experts are almost invariably specialists, while jacks-of-all trades are masters of none (Grant, 1996).

Implied in the principle of bounded rationality is the fundamental assumption that there are gains from specialization in knowledge acquisition and storage, and that production requires the input of a wide range of differentiated knowledge. Without benefits from specialization in knowledge there is no need for organizations comprising multiple individuals (Grant, 1996).

Therefore based on the principle of bounded rationality, it is assumed that individuals that make up organizations can be differentiated in terms of some specific, unique and bounded knowledge that they possess for meeting the needs of the relevant stakeholders of their organizations. However, because this knowledge may be tacit and not easily transferred to other organizational members, it therefore falls within the realm of human knowledge, as previously conceptualized in section two of this article. Albeit, this human knowledge that is resident within the individual is potentially useful for satisficing the needs of a particular stakeholder. Since stake holders are many, it becomes expedient to differentiate human knowledge according to the number of primary stakeholders often associated with organizations.

X-raying the vast literature on corporate social responsibility provides the identification of eight primary stakeholders. These are employees, shareholders, creditors, customers, competitors, suppliers, communities and government. What this implies is that a specific tacit human knowledge is always targeted towards meeting the needs one of these 
stakeholders at a given period of time. Therefore it will be useful to develop new concepts about human knowledge that effectively capture all organizational stakeholders. Towards this end, five new concepts pertaining to the different facets of human knowledge are presented. These are: (i) Human Knowledge about Product Market (HKPM) (ii) Human knowledge about Labour Market (HKLM) (iii) Human Knowledge about Financial Market (HKFM) (iv) Human knowledge about Technological Process (HKTP) (v) Human knowledge about External Environment (HKEE).

HKPM is tacit knowledge located within the minds of employees about the behaviour of customers in relation to products or services that the organization offers both its actual and potential markets. It also entails employees possessing some form of tacit knowledge about the behavioural orientation of customers towards competing products or services. Consequently, HKPM is basically directed to two organizational stakeholders. These are customers and competitors. However, its ultimate goal is to utilize the entire HKPM to satisfice the interests of customers.

HKLM corresponds to tacit knowledge domiciled within employees' minds about the nature of both internal and external labour markets in terms of the various skills, values, and competences required for organizational performance. HKLM directs attention to the sources of rare talents required to drive organizational value; as well as the utilization and development of such talents.

HKFM pertains to tacit knowledge resident within human minds about the most viable sources and applications of the firm's financial resources for increasing shareholders' wealth. It also has to do with knowledge about the impact of exigencies occurring within the financial markets on shareholders' wealth and credit worthiness of the organization. Hence HKFM focuses on satisficing the needs of shareholders and creditors.

HKTP addresses tacit knowledge about the various inputs, machines, equipment, etc., that is associated with the firm's process of production; as well as other alternatives to this production process. Suppliers of raw materials, valuable inventions and machines are the main stakeholders that HKTP is concerned with.

HKEE borders on tacit knowledge about the host communities, business laws, as well as the political climate and social values of the country in which business is conducted. HKEE focuses on two primary stakeholders. These are government and host communities.

In terms of quantity of human knowledge available to organizations, two key indicators can easily be identified. These are: organizational tenure of employees and number of employees focusing on all the differentiated forms of human knowledge. It is believed that the longer the employees remain in their organizations, the deeper would be the level of their organizational learning; which ultimately impacts positively on the ability of employees to generate new human knowledge. Also, the greater the numerical strength of employees that specialize in an area of human knowledge, the more likelihood of generating higher levels of human knowledge in this specialized area.

With regards to the quality of human knowledge available to the organization per time, two key indicators were identified. These are: number of trainings employees have undergone and the number of times employees in the five differentiated areas of human knowledge have been rewarded for generating a novel idea within a specific period of time.

The performance of the five types of human knowledge depends on both the quality and quantity of tacit knowledge that is resident in human minds about all organizational stakeholders at a specified period in time within organizations. Therefore, in order to identify the key indicators required for the measurement of their performance, these two parameters must be taken into account. 


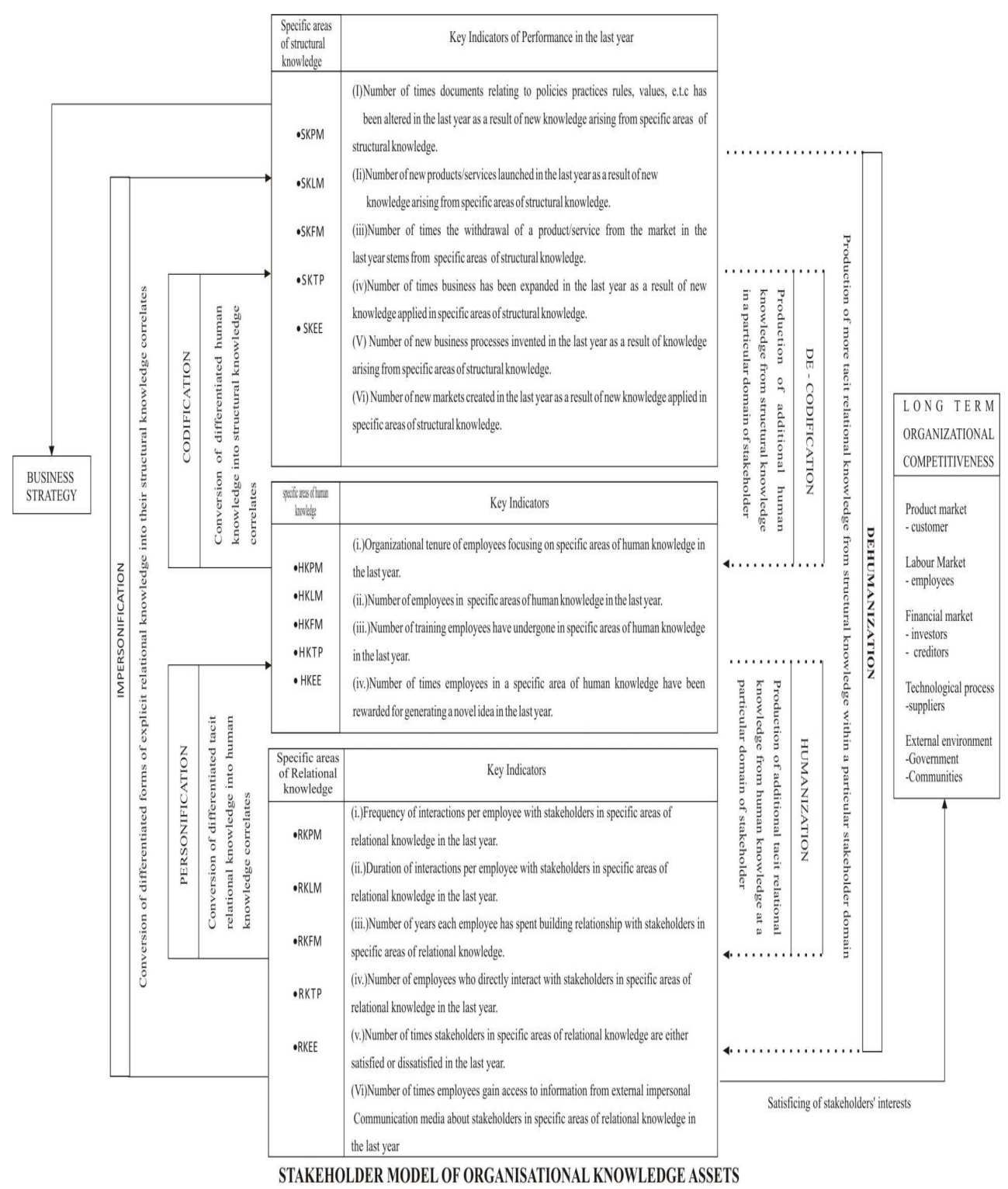

Fig. 1.

Hence four key indicators (organizational tenure, number of employees per time, number of employees' training per time, and number of times employees have been rewarded for generating a novel idea per time), would measure the performance of all the differentiated forms of human knowledge. 
But recall that the differentiated forms of human knowledge all exist in their tacit states. However, it is possible that over time, the different brands of human knowledge will be transformed into explicit knowledge. Through codification of human knowledge explicit knowledge is produced (Nonaka, 1994; Hansen, et. al., 1999; Lytras and Ordonez; 2009; Grover and Davenport, 2001; Becerra-Fernandez and Sabherwal, 2001). Once this is achieved, they cease to be called human knowledge. Rather they have been metamorphosed into their structural knowledge correlates.

Such metamorphosis yields the following conversions: HKPM is converted to Structural Knowledge about Product Market (SKPM). HKLM is converted to Structural Knowledge about Labour Market (SKLM). HKFM is converted to Structural Knowledge about Financial Market (SKFM). HKTP is converted to Structural Knowledge about Technological Process (SKTP). HKEE is converted to Structural Knowledge about External Environment (SKEE).

The codification process harnesses the differentiated forms of human knowledge to produce structural knowledge that is visible or shared amongst organizational members and aims at meeting the needs of stakeholders within the five areas of specialized knowledge. The codification process entails converting invisible human knowledge into visible structured knowledge that creates value for one or more stakeholders of organizations. Six of such visible end results that ensue the codification process are as follows: alteration of documents relating to policies, practices, rules, values, etc; the launching of new products and services; withdrawal of a product or service from the market; expansion of business activities through the establishment of new subsidiaries; invention of new business processes and the creation of new markets.

All of these visible end results which constitute the structural knowledge of organizations are propelled by specialized human knowledge in one or more of the five areas that encapsulate the interests of organizational stakeholders. These visible end results are the key indicators required for measuring the performance of structural knowledge.; and they periodically influence the direction of business strategy. It is for this reason that it would be impossible to extricate business strategy from structural knowledge; as changes in the formation of structural knowledge may often result to alterations in business strategy (De long and Fahey, 2000).

Nonetheless, both the formation and sharing of structural knowledge by organizational members leads to the production of more human knowledge. Unlike the direct conversion of the differentiated forms of human knowledge into their structural knowledge derivatives, already shared structural knowledge may not just produce its exact replica in the form of human knowledge. Instead through the process of de-codification, additional human knowledge could be produced from structural knowledge within the domain of a particular stakeholder.

For example, an organization may have an employment policy that forbids the employment of contract staff. This policy was informed by the experiences of those who have some HKLM. These persons have found out that past employees who have left the organization expropriate valued knowledge to competing firms. However, a new organizational specialist in HKTP, who has become conversant with the antecedents of this employment policy, may also become sensitive to the fact that inventors who are presently in the pay roll of the organization divulge valued ideas to outsiders for some personal gains.

From the above example, we can see that while HKLM led to generation of SKLM that forbids the employment of contract staff. However, this SKLM produced a new HKLM, which will need to be converted into its specific SKLM in order for the organization to guide 
against its inventors divulging important information to third parties. This observation leads to the first two propositions of this study which attempt to integrate human knowledge with structural knowledge, as shown below.

$\mathbf{H}_{\mathbf{1}}$ : The process of codification directly converts all differentiated forms of human knowledge into their structural knowledge derivatives.

$\mathbf{H}_{2}$ : De-codification of all sorts of structural knowledge would only increase human knowledge within the domain of a particular stakeholder.

The formation and sharing of structural knowledge that is explicit amongst employees should presupposedly guide and regulate the way they relate with their organizational stakeholders. Especially those employees that are directly interacting with stakeholders that have been affected by the structural knowledge that has been newly formed and shared. These employees would need to fully understand the impact of the newly formed structural knowledge on their stakeholders, and periodically adapt behaviours that would enable them maintain their relationships with the affected stakeholders. It is at this point that relational or social knowledge is reconstructed.

Relational knowledge is actually the knowledge asset that directly comes in contact with the stakeholders. It is that knowledge that organizations can directly access using their employees and also through formal and informal ties with their various stakeholders (Anand, et. al., 2002). It is important to note that just as we have the five differentiated forms of human and structural knowledge; relational knowledge can also be differentiated in terms of the stakeholder interests that it seeks to address. Hence the differiented forms of relational knowledge are as follows: (i) Relational Knowledge about Product Market (RKPM) (ii) Relational Knowledge about Labour Market (RKLM) (iii) Relational Knowledge about Financial Market (RKFM) (iv) Relational Knowledge about Technological Process (RKTP) and (v) Relational Knowledge about External Environment (RKEE).

However, because these differentiated forms of relational knowledge can either be in their tacit and explicit states (Anand, et. al; 2002), the processes by which they are integrated with human and structural knowledge are quite different. Tacit relational knowledge requires personal communication that allows for direct and intense interaction with a particular stakeholder. For instance, the tacit form of RKLM could only be acquired through intense personal interaction with members of both internal and external labour markets. When this effectively takes place, RKLM will be converted to HKLM, which in turn may be converted to SKLM via the codification process.

Nevertheless, the diffentiated forms of tacit relational knowledge are converted to their human knowledge correlates via the personification process (e.g. RKLM is converted to HKLM through the process of personification). This process involves the personification of tacit relational knowledge. Therefore, it can be assumed that as a specific form of tacit relational knowledge increases, its human knowledge correlate would also increase. This leads to the third proposition of this study, which is as follows:

$\mathbf{H}_{3}$ : The process of personification directly converts all differentiated forms of tacit relational knowledge into their human knowledge correlates; and so as relational knowledge of a particular stakeholder increases, its human knowledge correlate also increases.

Human knowledge obtained from relational knowledge can influence future interactions with a specific stakeholder to produce additional relational knowledge needed for dealing with the concerned stakeholder. For instance, through RKPM, it is possible for an organization to perceive that its customers are dissatisfied with its products or services. Through the personification process this RKPM is converted to HKPM, which subsequently 
could change future direct interactions with the customers to produce another RKPM that views its customers as being satisfied. Hence there is a process by which human knowledge generates additional form of relational knowledge within the domain of a specific stakeholder. This process is called humanization and so it can be posited that this process can produce more tacit relational knowledge that is quite different from the one that initially produced it. This leads to the fourth proposition of the study, which is as follows:

$\mathbf{H}_{4}$ : The process of humanization would lead to the production of additional tacit relational knowledge that derives from human knowledge within the domain of a particular stakeholder.

The process of humanization does not only produce more tacit relational knowledge. For it is possible to produce more tacit relational knowledge without the agency of the human mind. Since apart from personal interactions with stakeholders, relational knowledge can also be obtained explicitly from external sources through the use of impersonal communication media such as electronic data interchanges, internet, news papers, information from radio and TV stations (Anand, et. al; 2002); it could be possible to produce more tacit relational knowledge from these impersonal external sources. However, via a different process that is termed de-humanization. For the purpose of this article, the word "dehumanization" does not hold any English literary meaning. Rather, it serves to differentiate between accumulation of more tacit relational knowledge as a result of the functioning of the human mind (i.e. via humanization process) and the direct derivation of this knowledge via impersonal external sources that has been codified into structural knowledge required to satisfice the interests of a particular stakeholder. As a result of the import of the dehumanization process to the production of more tacit relational knowledge, the fifth proposition of this study is posed below.

$\mathbf{H}_{5}$ : The process of de- humanization would produce additional tacit relational knowledge that derives from structural knowledge within the domain of a particular stakeholder.

However, explicit relational knowledge within the domain of a particular stakeholder is directly converted into its structural knowledge correlate without the direct input of the human mind. The process of codifying explicit relational knowledge gained from impersonal external sources is termed impersonification. Thus, leading to the formulation of the sixth proposition, as shown below:

$\mathbf{H}_{6}$ : The process of impersonification directly converts explicit relational knowledge into structural knowledge within the domain of a particular stakeholder.

Like human and structural knowledge, the performance of relational knowledge can also be measured. Six key indicators can help us assess the performance of all differentiated forms of relational knowledge per time. These are: frequency of interactions per employee with stakeholders; duration of interactions per employee with stakeholders; number of years each employee has spent building relationship with stakeholders; number of employees who directly interact with stakeholders; number of times stakeholders in specific areas of relational knowledge are either satisfied or dissatisfied; number of times employees can gain access to information from external impersonal communication media about stakeholders in the specific areas of relational knowledge.

The six key indicators highlighted above for performance measurement of relational knowledge would enable organizations understand how they fare in terms of satisficing the interests of their stakeholders in a bid to gain long term organizational competitiveness.

It is worth noting that the above propositions about the interdependencies and interrelationships between the three types of knowledge assets (i.e. human knowledge, 
structural knowledge and relational knowledge) that are geared towards meeting the diverse interests of stakeholders have both theoretical and practical implications for managing organizations. This is treated in the next section of the article.

\section{Theoretical and practical managerial implications of the stake holder's model}

The knowledge based processes (i.e. codification, de-codification, personification, impersonification, humanization, and de-humanization) that integrate all the differentiated forms of human knowledge, structural knowledge and relational knowledge should occur discontinuously in organizations for them to sustain long term organizational competitiveness. In other words, organizations should strive to experience concurrent cycles of these processes. However, cycles of these processes would not just happen by abracadabra. Organizations must proactively ensure that the necessary conditions required for the effective management of these processes are created in order for them to successfully and continuously experience cycles of these processes.

First of all, modern organizations must embrace a stakeholder's perspective of conducting business. This suggests that they need to identify all their primary stakeholders and incorporate them into their business strategy. This is very imperative given the position held in this article that pinpoints the basis for the accumulation of all knowledge assets, which is, the satisficing of all stakeholders' interests. After organizations have been able to identify all their stakeholders, it would then be necessary to differentiate their employees based on areas of specialized knowledge that they possess in relation to these stakeholders. The stakeholder model of organizational knowledge assets depicted above recognizes five areas of such specialized knowledge. These are: human knowledge about product market(HKPM); human knowledge about labour market (HKLM); human knowledge about financial market (HKFM); human knowledge about technological process (HKTP), and human knowledge about external environment (HKEE).

The stakeholder model implies that all organizational employees would be located within the five broad areas of specialized knowledge needed for meeting the needs of business stakeholders. However, the main challenge lies in utilizing the tacit (human) knowledge that is domiciled within them in the five broad areas of specialized knowledge for the production of both structural and relational knowledge needed for the improvement of stakeholders' welfare. Recall that apart from the processes of de-humanization and impersonification, the other four processes (i.e. codification, de-codification, personification and humanization) cannot take place without the input of the human mind; and these four processes are needed for the formation of structural and relational knowledge. Human knowledge is precisely the conduit through which these four processes can be experienced in organizations. Consequently, there is need for us to place a lot of emphasis on managing this facet of organizational knowledge assets.

In his article on the Knowledge based theory of the firm, Grant (1996), dealt with two organizational variables that can influence the full expression of human knowledge. These are: the role of hierarchy and the distribution of decision making authority in organizations. According to Grant, the recent emphases for team based structures where team membership is fluid, depending upon the knowledge requirements of the task at hand, is one response to the deficiencies of hierarchy. The importance of a team based organization is the recognition that coordination is best achieved through the direct involvement of individual knowledge 
specialists, and that knowledge managers cannot effectively coordinate knowledge assets if they cannot harness the requisite specialist knowledge (Grant, 1996).

The spread of the team based approach to conducting business is occasioned by the notion that the critical knowhow is located among knowledge specialists. Hence the displacement of scientific management by various forms of participative, employee-empowering management approaches partly reflects the motivational benefits of these systems, but is also the result of the greater efficiency of these systems in harnessing and integrating the relevant human knowledge (Grant, 1996).

Also, in order to effectively harness human knowledge, the locus of decision making in organizations must be considered (Grant, 1996). According to Grant, the quality of organizational decisions depends on their being based upon the relevant human knowledge. If the human knowledge relevant to a particular decision can be concentrated at a single point in the organization, then centralized decision making is feasible. However, must of the time the human knowledge required to make decisions may be widely dispersed in organizations, and so it would be needful to deploy decentralized decision making to fully access and harness such knowledge(Grant, 1996).

The arguments brought forward by Grant lead to the submission that team based organizations that decentralize decision making to those who have relevant human knowledge would be favourably disposed to catalyzing the processes of codification, decodification, personification, and humanization required for the formation of structural and relational knowledge that could improve stakeholders' welfare.

However, while variables that pertain to organizational structure and decision making as delineated above by Grant(1996), may be very important for the harnessing and accessing of human knowledge; contemporary research in knowledge management has ignored the import of personal factors in the expression of human knowledge. Organizations can design their structures in ways that facilitate the production of structural and relational knowledge from human knowledge; however, if individuals lack motivation, job satisfaction and commitment towards their organizations, they may resist the utilization of their tacit human knowledge. This challenge leads the discussion to the concept of knowledge markets.

Grover and Davenport (2001), aver that organizations should be seen as knowledge markets in which knowledge is exchanged for other things of value- money, respect, promotions, or other knowledge. The concept recognizes the interest that individuals have in holding onto the knowledge they possess (Grover and Davenport, 2001). Yet there is paucity of research on the behavior of various knowledge markets. For instance, the capacity of organizations to unleash tacit human knowledge about product market, labour market, financial market, technological process and external environment, may vary depending on the behavior of specialists in the five different knowledge markets.

Therefore for organizations to constantly experience the dynamics of the knowledge based processes (i.e. codification, de-codification, personification, and humanization) that must depend on the functioning of the human mind, both organizational and personal variables that could influence the production of structural and relational knowledge from human knowledge must be given considerable attention by knowledge assets' managers. But in addition to these, the four key indicators (i.e. organizational tenure of employees, number of employees focusing on all differentiated areas of human knowledge, number of trainings employees have undergone per time, number of employees in all differentiated areas of human knowledge that have been rewarded for generating a novel idea within a specific period of time), required for tracking down the performance of all brands of human 
knowledge must be regularly monitored to ensure the flourishing of these four processes in organizations.

The other two processes (i.e. de-humanization and impersonification) which enable the addition of stocks of explicit knowledge to differentiated forms of relational knowledge and structural knowledge without the rigorous functioning of the human mind can be kept alive in organizations by exploring and exploiting various impersonal sources of information that expose organizational members to the interests of their stakeholders.

Finally, the discontinuous functioning of all the six knowledge based processes also depends on the nexus between structural knowledge that has been shared amongst all organizational employees and the sustenance of the network of relationship that the organization has with its stakeholders. As already stated in an earlier section of this article, organizational structural knowledge would always influence business strategy and this should not adversely affect the network of relationship between organizations and their stakeholders. Consequently, structural knowledge and relational knowledge must mutually reinforce each other in order for these integrative processes to concurrently and discontinuously produce the different forms of knowledge assets needed for long term organizational competitiveness.

\section{Conclusion}

With the emergence of the knowledge driven economy, knowledge assets have become the most important factor of production in $21^{\text {st }}$ century organizations. This therefore suggests that knowledge assets should drive the long term competitiveness of these organizations. However, without satisficing the pluralized interests of stakeholders, it would be impossible for knowledge assets to achieve this objective.

This present article has identified six different processes (i.e. codification, de-codification, personification, impersonification, humanization, and de-humanization) by which different knowledge assets (i.e. structural knowledge, human knowledge and relational knowledge) can be synchronized or integrated with a business strategy that seeks the satisficing of organizational stakeholders' interests.

It is worth noting that for the very first time in the history of knowledge management, the interrelationships and interdependencies between the different knowledge assets; and the ways by which they create value for organizations was well delineated by the stakeholder model that was developed in this study.

Further more, with the use of extant material in the field of knowledge management, it was impossible to define the functionality of all the different knowledge assets. However, this problem has been largely ameliorated through the purpose driven differentiation typology adopted for the naming of these knowledge assets. Based on this typology, any facet of these assets could be specifically targeted by knowledge assets' managers for performance improvement.

Most importantly, this purpose driven differentiation of knowledge assets is superior to extant categorization of knowledge assets because it affords us the opportunity of properly discerning the key indicators required for tracking down the performance of these knowledge assets; as well as providing the leeway for their effective management to the betterment of organizational stakeholders for long term organizational competitiveness.

It is suggested here that empirical studies should be undertaken to test the various propositions posed in this study; as this would help validate the veracity of the six 
aforementioned processes that integrate the different types of knowledge assets. Finally, one philosophical stance of this article hinges on employees' knowledge specialization; but it may be possible for an employee to possess some tacit knowledge in two or more areas of specialized knowledge. Such situations in which some employees may be jack of all trades will be the subject of another article.

\section{References}

Akbar, H. (2003). "Knowledge Levels and their Transformation: Towards the Integration of Knowledge Creation and Individual Learning", Journal of Management Studies, Vol. 40: 1998-2019.

Alas, R. (2009). “Organizational Learning During Changes in Estonian Organizations" in Lytras, M. and Ordonez de Pablos, P. (eds.) (2009). Knowledge Ecology in Global Business: Managing Intellectual Capital, New York: Information Science Reference.

Alavi, M. and Leidner, D. (2001). "Knowledge Management and Knowledge Management Systems: Conceptual Foundations and Research Issues", Management Information Systems, Vol. 25, No. 1: 107-136.

Anand, V.; Glick, W.; and Manz, C. (2002). "Thriving on the Knowledge of Outsiders: Tapping organizational Social Capital", Academy of Management Executive, Vol. 16. No. 1: 87-101.

Andriessen, D. (2004). Making Sense of Intellectual Capital, Elsevier Butterworth Heinemann: Burlington.

Barney, J. (1986). "Strategic Factor Markets: Expectations, Luck, and Business Strategy", Management Science, Vol. 32: 1231-1241.

Barney, J. (1991). "Firm Resources and Sustained Competitive Advantage", Journal of Management, Vol 17: 99-120.

Becerra- Fernandez, I. and Sabherwal, R. (2001). “Organizational Knowledge management: A Contingency Perspective", Journal of Management Information Systems, Vol 18. No. 1: 23-55.

Bontis, N. (1996). "There's a Price on your Head: Managing Intellectual Capital Strategically", Business Quarterly, Summer, 41-47.

Bontis, N., Chong, W., and Richardson, S. (2000). "Intellectual Capital and Business Performance in Malaysian Industries," Journal of Intellectual Capital, Vol 1, No 1: 85100.

Carroll, A. (1989). Business and Society, Cincinnati: South Western, 2nd Edition.

Chang, S. and Lee, M. (2007). "The Effects of Organizational Culture and Knowledge Management Mechanisms on Organizational Innovation: An Empirical Study in Taiwan", The Business Review, Cambridge, Vol 7. No 1: 295- 301.

Cuganesan, S. (2005). "Intellectual Capital in Action and Value Creation", Journal of Intellectual Capital, Vol. 6, No. 3: 357-373.

Cyert, R. and March, J. (1963). A Behavioural Theory of the Firm, Englewood Cliffs, N.J.: Prentice Hall.

De Long, D. and Fahey, L. (2000). “Diagnosing Cultural Barriers to Knowledge Management", Academy of Management Executive, Vol. 14, No. 4: 113-127.

Edvinsson, L. and Malone, M.(1997). Intellectual Capital: Realizing your Company's True Value of Finding its Hidden Brain power, New York: HarperCollins. 
Falconer, J.(2011). "Rewinding History: Paradoxes, Evanescence, and Hubris in Learning/Knowledge Exploration, International Journal of Learning and Intellectual Capital, Vol. 8, No. 1: 18-29.

Freeman, R. (1984). Strategic Management: A Stakeholder Approach, Marshfield (MA): Pitman.

Freeman, R. (2002). "A Shareholder Theory of the Modern Corporation" in P. Hartman (ed), Perspectives in Business ethics, London: Mc Graw Hill, 171-181pp.

Friedman, M. (2002). Capitalism and Freedom, Chicago: University of Chicago Press.

Grant, R. (1996). "Toward a Knowledge Based Theory of the Firm", Strategic Management Journal, Vol. 17: 109-122.

Grover, V. and Davenport, T. (2001). “General Perspectives on Knowledge Management: Fostering a Research Agenda", Journal of Management Information Systems, Vol. 18. No. 1: 5-21.

Grover, V. and Davenport, T. (2001). “General Perspectives on Knowledge Management: Fostering a Research Agenda", Journal of Management Information Systems, Vol. 18, No. 1: 5-21.

Hansen, M.; Nohria, N.; and Tierney, T. (1999). “What's your Strategy for Managing Knowledge?", Harvard Business Review, March-April Issue: 106-116.

Hillman, A. and Keim, G. (2001). "Shareholder Value, Stakeholder Management, and Social Issues: What's the Bottom Line?", Strategic Management Journal, Vol. 22, No. 2: 125139.

Ho, C. (2007). "Identifying Stakeholders' Position through Value Creation System", The Business Review, Cambridge, Vol 7. No 1: 254-262.

Houghton, J. and Sheetan, P. (2000). "A Primer on the Knowledge Economy", Centre for Strategic Economic Studies, Victoria University, Australia.

Hsu, H. (2009). "Managing the Information Technology: Knowledge Transfer in Virtual Teams", in Lytras, M. and Ordonez de Pablos, P. (eds.) (2009). Knowledge Ecology in Global Business: Managing Intellectual Capital, New York: Information Science Reference.

Joia, L. and Sanz, P. (2009). “The Conundrum of Valuing a Company's Intellectual Capital: The Role of Taken for Granted Indicators", in Lytras, M. and Ordonez de Pablos, P. (eds.) (2009). Knowledge Ecology in Global Business: Managing Intellectual Capital, New York: Information Science Reference.

Kaplan, R. and Norton, D. (1992). "The Balanced Scorecard- measures that drive performance" Harvard Business Review, January- February: 72-79.

Kaplan, R. and Norton, D. (1993). "Putting the Balanced Scorecard to Work", Harvard Business Review, September-October: 134-147.

Kaplan, R. and Norton, D. (1996). “Using the Balanced Scorecard as a Strategic Management System", Harvard Business Review, January-February, 76.

Lytras, M. and Ordonez de Pablos, P. (2009). "The Building of the Intellectual Capital Statement in Multinationals: Challenges for the Future" in Lytras, M. and Ordonez de Pablos, P. (eds.) (2009). Knowledge Ecology in Global Business: Managing Intellectual Capital, New York: Information Science Reference.

Malhotra, Y. (2000). "Knowledge Assets in the Global Economy: Assessment of National Intellectual Capital", Journal of Global Information Management, Vol 8, No. 3: 5-15.

March, J. and Simon, H. (1958). Organizations, New York: Wiley. 
Markus, M. (2001). “Toward a Theory of Knowledge Reuse: Types of Knowledge Reuse Situations and Factors in Reuse Success", Journal of Management Information Systems, Vol. 18, No 1: 57-93.

Menon, T. and Pfeffer, J. (2003). "Valuing Internal vs External Knowledge: Explaining the Preference for Outsiders", Management Science, Vol. 49, No. 4: 497-513.

Nasi, J. (1982). “Towards a Deeper Comprehension of the Social Responsibility of Firms: Some Philosophical, Conceptual and Methodological Frameworks for Scientific Research", Turku School of Economics and Business Administration, Series A.

Nasi, J. (1995). (ed.) Understanding Stakeholder Thinking, Helsinki: LSR-Publications.

Neilsen, C., Roslender, R., and Bukh, P. (2009). " Intellectual Capital Reporting: Can a Strategy Perspective Solve Accounting Problems?" in Lytras, M. and Ordonez de Pablos, P. (eds.) (2009). Knowledge Ecology in Global Business: Managing Intellectual Capital, New York: Information Science Reference.

Nonaka, I. (1994). “A Dynamic Theory of Organizational Knowledge Creation”, Organization Science, Vol. 5, No 1: 14-37.

Ordonez de Pablos, P. (2001). "Relevant Experiences on Measuring and Reporting Intellectual Capital in European Pioneering Firms", in N. Bontis and C. Chong (eds.), Organizational Intelligence: The Cutting Edge of Intellectual Capital and Knowledge Management, London: Butterworth-Heinemann

Ordonez de Pablos, P. (2004). "Knowledge Flow Transfers in Multinational Corporations: Knowledge Properties and Implications for Management" Journal of Knowledge Management, Vol 8, No 4: 105-116.

Ordonez de Pablos, P. (2005). "Intellectual Capital Accounts: What Pioneering Firms from Asia and Europe are doing Now." International Journal of Knowledge and Learning, Vol 1. No 3: 249-268.

Penrose, E. (1959). The Theory of the Growth of the Firm, Wiley: New York.

Petty, R. and Guthrie, J. (2000). "Intellectual Capital Literature Review”, Journal of Intellectual Capital, Vol. 1: 155-176.

Polanyi, M. (1962). "Personal Knowledge", in Meaning, M. Polanyi and H. Prosch (eds.) (1975), Chicago: University of Chicago Press, pp22-45.

Quinn, B. (2005). "The Intelligent Enterprise of a New Paradigm", Academy of Management executive, Vol. 19, No. 4: 109-120.

Rumelt, R. (1984). “Towards a Strategic Theory of the Firm”, In R.B. Lamb (ed.), Competitive Strategic Management, Prentice-Hall: Englewood Cliffs, N.J.

Rumelt, R. (1987). "Theory, Strategy, and Entrepreneurship", in D. Teece (ed.), The Competitive Challenge, Ballinger: Cambridge, MA. pp.556-570.

Saenz, J. and Gomez, J. (2008). "Intangible Disclosure, Market Performance and Business Reputation- the case of Spain", International Journal of Learning and Intellectual Capital, Vol. 5, No. 1: 83-99.

Schneider, M. (2002). "A Stakeholder Model of Organizational Leadership", Organization Science, Vol. 13, No. 2: 209-220.

Schuima, G. (2009). "Strategies for Assessing Organizational Knowledge Assets" in Lytras, M. and Ordonez de Pablos, P. (eds.) (2009). Knowledge Ecology in Global Business: Managing Intellectual Capital, New York: Information Science Reference.

Shafritz, J. and Ott, S. (1996). Classics of Organization Theory, New York: Harcourt Brace College Publishers. 
Simon, H. (1982). Models of Bounded Rationality, Vols. 1 and 2, MIT Press.

Simon, H. (1991). "Bounded Rationality and Organizational Learning", Organization Science, Vol. 2: 125-134.

Skandia. (1996). Customer Value. Supplement to Skandia's 1996 Annual Report.

Spender, J. (1994). "Organizational Knowledge, Collective Practice and Penrosian rents", International Business Review, Vol. 3: 353-367.

Stewart, T.(1997). Intellectual Capital: The New Wealth of Organizations, New York: Doubleday/Currency.

Studdard, N. and Darby, R. (2011). “Social Entrepreneurship: Managing Strategic Decisions in Social Entrepreneurial Organizations", International Journal of Social Entrepreneurship and Innovation, Vol 1. No. 1: 66-78.

Sveiby, K. (1997). The New Organization Wealth: Managing and Measuring Knowledge Based Assets, San Francisco: Berett-Koehler.

Teece, D.; Pisano, G. and Shuen, A. (1997). “Dynamic Capabilities and Strategic Management", Strategic Management Journal, Vol. 18: 509-533.

Tongo, C. (2008). "Building the Intellectual Capital of African Enterprises in a Knowledge Economy: Impediments and Requirements", International Journal of Learning and Intellectual Capital, Vol 5. No 1: 33-47.

Tongo, C. (2010). Accounting for Intellectual Capital: A 21 Strategic Managers, Journal of Management Systems, Vol. 22, No. 1: 39-51.

Tsang, W. and Chang, C. (2005). "Intellectual Capital System Interaction in Taiwan", Journal of Intellectual Capital, Vol. 6, No. 2: 285-298.

Wernerfelt, B. (1984). “The Resource Based View of the Firm”, Strategic Management Journal, Vol. 5: 171-174.

Winter, S. (1988). "Knowledge and Competence as Strategic Assets", In D. Teece (ed.), The Competitive Challenge: Strategies for Industrial Innovation and Renewal, Ballinger, Cambridge, MA. 


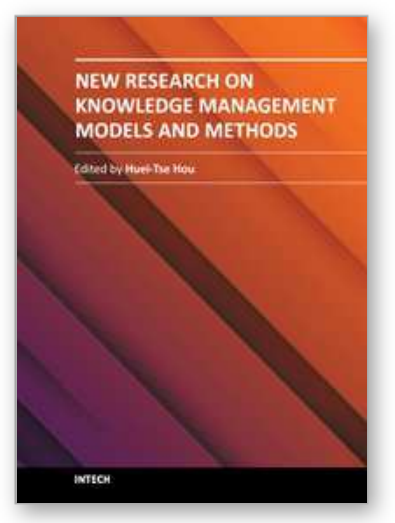

\author{
New Research on Knowledge Management Models and Methods \\ Edited by Prof. Huei Tse Hou
}

ISBN 978-953-51-0190-1

Hard cover, 426 pages

Publisher InTech

Published online 23, March, 2012

Published in print edition March, 2012

Due to the development of mobile and Web 2.0 technology, knowledge transfer, storage and retrieval have become much more rapid. In recent years, there have been more and more new and interesting findings in the research field of knowledge management. This book aims to introduce readers to the recent research topics, it is titled "New Research on Knowledge Management Models and Methods" and includes 19 chapters. Its focus is on the exploration of methods and models, covering the innovations of all knowledge management models and methods as well as deeper discussion. It is expected that this book provides relevant information about new research trends in comprehensive and novel knowledge management studies, and that it serves as an important resource for researchers, teachers and students, and for the development of practices in the knowledge management field.

\title{
How to reference
}

In order to correctly reference this scholarly work, feel free to copy and paste the following:

Constantine Imafidon Tongo (2012). A Stakeholder Model for Managing Knowledge Assets in Organizations, New Research on Knowledge Management Models and Methods, Prof. Huei Tse Hou (Ed.), ISBN: 978-95351-0190-1, InTech, Available from: http://www.intechopen.com/books/new-research-on-knowledgemanagement-models-and-methods/a-stakeholder-model-for-managing-knowledge-assets-in-organizations

\section{INTECH}

open science | open minds

\author{
InTech Europe \\ University Campus STeP Ri \\ Slavka Krautzeka 83/A \\ 51000 Rijeka, Croatia \\ Phone: +385 (51) 770447 \\ Fax: +385 (51) 686166 \\ www.intechopen.com
}

\author{
InTech China \\ Unit 405, Office Block, Hotel Equatorial Shanghai \\ No.65, Yan An Road (West), Shanghai, 200040, China \\ 中国上海市延安西路65号上海国际贵都大饭店办公楼 405 单元 \\ Phone: +86-21-62489820 \\ Fax: +86-21-62489821
}


(C) 2012 The Author(s). Licensee IntechOpen. This is an open access article distributed under the terms of the Creative Commons Attribution 3.0 License, which permits unrestricted use, distribution, and reproduction in any medium, provided the original work is properly cited. 